\title{
Predictors of unmet needs in Chilean older people with dementia: a cross-sectional study
}

Thamara Tapia Muñoz ${ }^{1}$, Andrea Slachevsky ${ }^{2,3,4,5,6}$, María O. León-Campos ${ }^{8}$, Michel Madrid ${ }^{8}$, Alejandra Caqueo-Urízar ${ }^{9}$, Gustav C. Rohde ${ }^{10}$ and Claudia Miranda-Castillo $0^{7,8^{*}}$ (D)

\begin{abstract}
Background: The needs of people with dementia (PWD) have not been assessed in any Latin American country. Several European countries have already related unmet needs with quality of life, caregiver's age, burden, stress, anxiety and depression. The aim of this study was to identify met and unmet needs in Chilean older adults with dementia and to determine if those needs were associated with PWD's, their informal caregivers' and social factors.

Method: This was a cross-sectional study. One-hundred and sixty-six informal caregivers and their care recipients were interviewed. PWD was assessed about cognitive function and their caregivers answered instruments about PWD's needs, functional status and behavioral and psychological symptoms. Caregiver's burden, depression, anxiety and social support were also evaluated. A stepwise multiple linear regression analysis was performed to determine predictors of unmet needs in Chilean PWD.

Results: The most frequent met needs were "Looking after home" (81.3\%\%), "Food" (78.9\%) and "Selfcare" (75.3\%). Most common unmet needs were "Daily living activities" (39.2\%), "Company" (36.1\%), and "Memory" (34.9\%).

Caregivers' lower age was correlated to a higher number of PWD's unmet needs $\left(r_{s}=-.216 ; p<0.005\right)$. Higher PWD's dependence was associated with higher number of unmet needs $\left(r_{s}=.177 ; p<0.05\right)$. The best predictors of unmet needs were caregivers' low level of social support, high burden, young age and high level of anxiety.

Conclusion: It is necessary to address psychological and social needs of PWD. The fact that PWD's unmet needs were associated mostly with caregivers' factors, highlights the importance of considering both, the PWD and their informal caregivers as targets of institutional support. It is expected that recently launched national public policies decrease PWD's unmet needs by the provision of new services for them and their informal caregivers.
\end{abstract}

Keywords: Needs, Dementia, Older people, Social support, Caregivers, Alzheimer's disease, Mental health

\section{Background}

Over 47 million of people have dementia worldwide [1]. Every year there is an approximate increase of 7.7 million cases at a global scale, which means a new case arises every 4 sec [2]. Dementia research has relied mostly in the biomedical model (etiology and treatment) without considering the psychological and social aspects of the disease [3].

\footnotetext{
* Correspondence: claudia.miranda@unab.cl

${ }^{7}$ Universidad Andres Bello, Faculty of Nursing, Sazié 2212, Santiago, Chile ${ }^{8}$ Millennium Institute for Research in Depression and Personality (MIDAP), Santiago, Chile

Full list of author information is available at the end of the article
}

In Chile, it has been estimated that $1.06 \%$ of the population over 60 years old (around 200,000 people) have some kind of dementia $[4,5]$. Dementia care has been mostly a family responsibility, with isolated actions from the healthcare system such as a primary care screening for cognitive impairment and dementia [6,7]. Chile is currently starting to pilot the first national strategy for dementia, which includes new initiatives to address this condition $[8,9]$. In this context, in order to provide appropriate interventions and social services, the assessment of needs in PWD becomes crucial $[6,10,11]$. Needs can be studied considering the person's own perspective (subjective need) or through the perception of a

(c) The Author(s). 2019 Open Access This article is distributed under the terms of the Creative Commons Attribution 4.0 International License (http://creativecommons.org/licenses/by/4.0/), which permits unrestricted use, distribution, and reproduction in any medium, provided you give appropriate credit to the original author(s) and the source, provide a link to the Creative Commons license, and indicate if changes were made. The Creative Commons Public Domain Dedication waiver (http://creativecommons.org/publicdomain/zero/1.0/) applies to the data made available in this article, unless otherwise stated. 
third one (objective needs). In the case of old adults with dementia, this external person usually is an informal caregiver or a health professional $[12,13]$.

The needs of PWD have already been studied in European countries. According with those studies, unmet needs are related with behavioral and psychological symptoms of dementia (BPSD), caregiver's age, burden, stress, anxiety and depression [10, 14-16]. However, those results cannot be generalizable to Latin American countries, including Chile, mainly because, as a consequence of the lack of developed health and social services that can meet the needs of persons with dementia, most of the care and cost of the disease relies on informal care [17-19]. Therefore, research on PWD's needs in non-developed countries can illustrate how met and unmet needs vary according to the provision of health and social services.

The present work is the first study to assess the needs of PWD in a Latin-American country. The aim of this study was to identify met and unmet needs in Chilean older adults with dementia and to determine if there was a relation between their needs and personal, social and caregivers' factors. It was hypothesized that (a) PWD being looked after by a younger caregiver would have higher number of unmet needs and (b) PWD being cared for by a caregiver with poor mental health (high levels of depressive or anxiety symptoms, and/or burden) would have higher number of unmet needs.

\section{Method \\ Sample}

This was a cross-sectional study with a non-probability convenience sampling. One-hundred and sixty-six informal caregivers and their relatives with dementia were interviewed. Initially, 288 potential participants were approached. Out of these, 35 persons were excluded because they did not meet the inclusion criteria as follows: 13 had been institutionalized, 8 did not meet the criteria for dementia, 3 were younger than 60 years old and 11 had died, leaving a total of 253 people suitable to be included in the study. Out of these, 39 could not be reached by researchers and 9 were too confused when contacted by phone that they could not consent to be approached in person. Of the 205 remainder, 39 refused to take part in the study. Some of the reasons for refusing included not wanted to be bothered, not receiving any direct benefit from participating, or reason not known (Fig. 1).

Participants were contacted from different organizations, enrolled through advertisement or referred by a neurologist. The inclusion criteria for informal

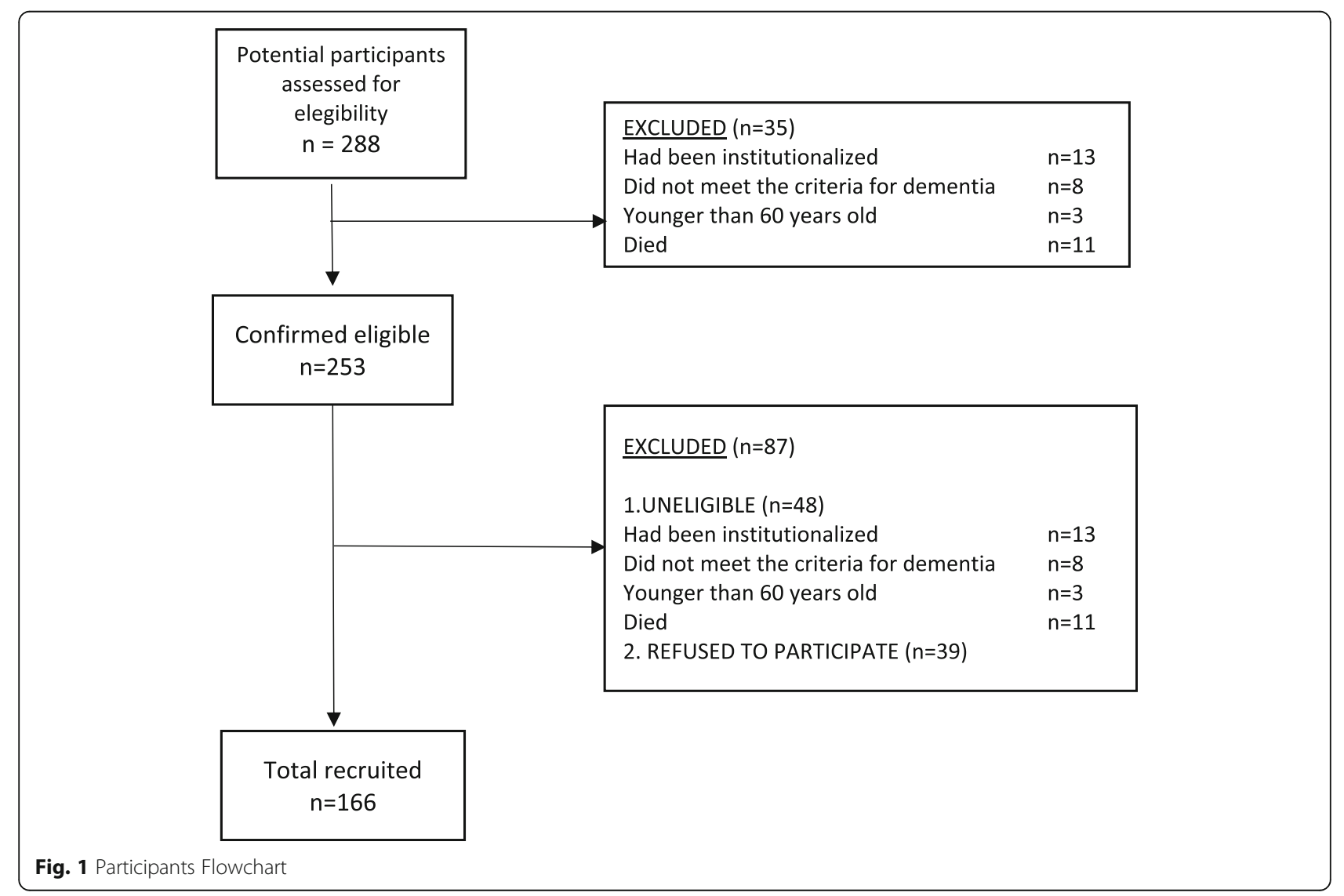


caregivers were: consider themselves as principal caregivers and not being receiving any formal payment as a caregiver. Criteria for PWD were: being 60 or over, diagnosed with any type of dementia by a physician and being living at their own homes. This research was approved by the Bioethical Committee of the Faculty of Medicine, Universidad de Valparaíso.

\section{Consent procedure}

All interviews were carried out either, at PWD's or caregiver's homes. Once there, the interviewer answered any queries and tried to obtain informed consent as follows: a written consent by signing a consent form was required from PWD and their caregivers. Some persons with dementia were unable to provide written informed consent. When this occurred, the interviewer obtained caregiver's consent and also sought the person with dementia's assent. During this process, the interviewer made sure that he/she had taken as much time and care in explaining the information about this research as simply as possible. The interviewer avoided using long sentences and attempted to reduce any distractions. To find out if the participants have understood the information given, the interviewer observed their ability to ask any relevant questions and also requested the participant to repeat back the information and how it would relate to them. In addition, the interviewer clarified any doubts about the study and reiterated about the right to withdraw at any time.

\section{Interviews}

Whenever possible, the person with dementia and the caregiver were interviewed separately. Only few caregivers wanted to be present at PWD's cognitive impairment assessment (11\%). Interviews were terminated immediately in presence of any sign of discomfort. Using standardized instruments, PWD were interviewed about their cognitive status. Caregivers were interviewed about the PWD's sociodemographic details, needs, behavioral and psychological symptoms and functional status. In addition, caregivers were assessed about their own sociodemographic details, depression, anxiety, burden and social support. This interview took about $1 \mathrm{~h}$ and a half. The interviewer started the assessment reminding participants what the interview was about and answering any questions they might have. After that, informed consent was sought according to the procedure stated above. There was no particular order to administer the instruments, but usually the interview with the caregiver started with the instrument for assessing needs (CANE).

It is important to mention that the data for this study was collected previous to the recent pilot implementation of national policies regarding PWD's care.

\section{Materials \\ Instruments administered to the person with dementia}

Mini mental state examination (MMSE) This test assesses cognitive function. It has been widely used in clinical and research practice. The Chilean validation of the MMSE showed a high sensibility 93.6\% (95\% CI 70.6-99.7\%) and specificity 46.1\% (95\% CI $34.7-57.8 \%)$ [20].

\section{Instruments administered to the caregiver to obtain information about the person with dementia}

Camberwell assessment of need for the elderly (CANE) A comprehensive tool which offers a structured evaluation of needs in older people in 24 areas of social, psychological, physical, and environmental needs rated as no need, met need or unmet need. It assesses the needs of older people from the perspective of the PWD, the caregiver, the staff and the researcher. The CANE has shown good levels of reliability $(\mathrm{a}=0.99)$ and validity (correlated with the CAPE-BRS, $r=0.66$; and the Barthel $r=-0.53$ ) [21]. The Spanish version had good reliability (inter-observer $0.60-1$ and test retest $0.65-1$ ). Also it had a criterion validity coefficient of 0.81 [22]. In our study, only caregivers' report about PWD's needs have been considered.

Barthel index of activities of daily living This tool assesses functional status of a person. Its scores can be categorized into five levels: total, severe, moderate or mild dependence, and autonomy. The instrument has shown good reliability: intra-observer Kappa indexes between 0,47 and 1, inter-observer concordance Kappa indexes between 0.84 y 0.97 and Cronbach's alpha coefficient between de 0.86 and 0.92 [23].

\section{Neuropsychiatric inventory questionnaire (NPI-Q)} The NPI-Q is a structured interview designed to assess a broad range of behavioral and psychological symptoms commonly encountered in PWD. This tool has shown high internal consistency reliability for the frequency/severity product scores $(\mathrm{a}=0.88)$ and for the specific severity $(\mathrm{a}=0.87)$ and frequency $(\mathrm{a}=0.88)$ ratings [24]. The brief version of this scale, the NPI-Q, was validated in Chile with excellent results [25]. The test-retest showed a significant correlation for total symptoms scale $(r=0.89)$ and for distress scale $(r=$ 0.90). Convergent validity between NPI-Q and NPI revealed a high correlation for total symptoms and for distress scale $(r=0.88 ; r=0.92)$ [26]. 


\section{Instruments administered to the caregiver to obtain information about themselves}

ZARIT burden interview (ZARIT) This tool measures the stress perceived by caregivers about activities related to the support and care of a relative. It is composed by 22 items and the Chilean validation performed remarkable values of internal consistence (0.87), inter observer reliability (0.86) and test retest reliability (0.91) [27].

Hospital anxiety and depression scale (HADS) This scale was developed to assess anxiety and depression symptoms in no clinical populations. The scale has 14 items divided into two subscales: anxiety (HADS-A) and depression (HADS-D) each one includes 7 items. The Spanish version has a test-retest reliability coefficient over 0.85. Its internal consistency was 0.86 (HADS-A) and 0.86 (HADS-D) [28].

Multidimensional scale of perceived social support This tool measures the characteristics of the social network according to the perception of the subjects. It is composed by 6 items scored from 1 to 4 (1: Never, 2: Sometimes, 3: Frequently, 4: Always). It has shown good psychometric properties with a Cronbach's alpha from 0.70 to 0.79 [29]. The Chilean validation of this instrument was done with elderly population revealing a good reliability (Cronbach's 0.86) [30].

\section{Data analysis}

A statistical analysis was performed with IBM SPSS Statistics 21 software package [31, 32]. Descriptive statistics were carried out to assess demographic information and characteristics of met/unmet needs (mean, standard deviation, range and frequency in percentages). The factors associated with unmet needs were analysed using Spearman correlation. Mann-Whitney test was done for the variables caregiver's sex and PWD's sex and Kruskall Wallis test was performed with the variable "relationship with the PWD". All analyses were carried out at significance level of $p<0.05$ and $p<0.01$. In addition, a stepwise multiple linear regression analysis was done to determinate the predictors of unmet needs of PWD. The dependent variable was the unmet needs of PWD and independent variables were PWD's functional status, and caregiver's social support, burden, age, relationship with PWD, anxiety and depressive symptoms.

\section{Results}

Demographic and clinical characteristic of people with dementia

Demographic and clinical characteristics of PWD are shown in Table 1 . The age of PWD ranged from 63 to
108 years $(M=80.3$, s.d. $=7.9)$. There were $66.7 \%$ of women and $33.3 \%$ were men. A similar percentage of PWD were either married/with partner or widowed (48.8 and $47.6 \%$ respectively). Related to the educational background, $40.2 \%$ of older adults with dementia did not complete primary school.

The results of the mini mental (MMSE) showed that $18.9 \%$ of them had severe cognitive impairment, $55.9 \%$ had moderate and $25.2 \%$ had mild cognitive impairment. The results of the Barthel Index showed that $18.4 \%$ had total dependence, $14.7 \%$ severe dependence, $12.9 \%$ moderate dependence, $44.7 \%$ mild dependence and 9.2\% were autonomous. Finally, the most frequent behavioral and psychological symptoms were depression/dysphoria (79.9\%), anxiety (72.6\%) and apathy (69.5\%).

\section{Demographic and clinical characteristic of caregivers}

Table 2 shows demographic and clinical characteristics of caregivers. The mean age was 57.6 (s.d.= 14.5) and ranged from 22 to 96 years. Most of the participants were women (81.9\%) and have a spouse/ partner $(66.9 \%)$. Around $55 \%$ were a son/daughter and $28.3 \%$ were spouses of the PWD. Regarding the clinical characteristics of caregivers, 68.9\% (95\% IC = 61.5-75.2\%) presented intense burden, $60.7 \%(95 \%$ IC $=53.4 \%-68-1 \%)$ had depressive symptoms and $66.9 \%(95 \%$ IC $=59.5-74.2 \%)$ of them had anxiety symptoms.

\section{Needs}

The mean of total number of needs was 13.3 (s.d. = 4.52; range $0-25$ ) and out of these 10 were met needs (s.d. = 3.86; range $0-20$ ) and 3.3 were unmet needs (s.d. $=2.82$; range 0-13). The frequency of CANE met and unmet needs by area are shown in Tables 3 and 4. The most frequent met needs of PWD were found in the environmental area: "Money" (82.5\%), "Looking after home" (81.3\%), "Food" (78.9\%). Some physical needs were also mostly met, such as "Self-care" (75.3\%) and "Physical health" (57.2\%).

The most common unmet needs were social and psychological, such as "Daily activities" (39.2\%), "Company" (36.1\%), and "Memory" (34.9\%); followed by "Information" (27.1\%) and "Psychological distress" (21.1\%).

\section{Factors associated with unmet needs}

Table 4 shows there was a significant relation between low level of caregivers' social support and more unmet needs in PWD $\left(\mathrm{r}_{\mathrm{s}}=-.383 ; p<0.01\right)$. Moreover, caregivers who were children of the PWD $(\mathrm{K}-\mathrm{W}=7.307 ; p<0.05)$ and younger $\left(\mathrm{r}_{\mathrm{s}}=-.216 ; p<0.01\right)$ reported higher number of unmet needs. Additionally, high levels of caregivers' burden $\left(\mathrm{r}_{\mathrm{s}}=.372 ; p<0.01\right)$, depressive symptoms $\left(\mathrm{r}_{\mathrm{s}}=.354 ; p<0.01\right)$ and anxiety symptoms $\left(\mathrm{r}_{\mathrm{s}}=.260 ; p=\right.$ 
Table 1 Demographic and Clinical Characteristic of People with dementia

\begin{tabular}{|c|c|c|c|c|c|}
\hline Characteristic & N & & $\%$ & $95 \%$ IC & $\begin{array}{l}\text { Mean/s.d. } \\
95 \% \text { IC }\end{array}$ \\
\hline \multirow[t]{3}{*}{ Age } & 165 & $60-73$ & 20 & $13.9-26.7$ & \\
\hline & & $74-83$ & 45.5 & $38.2-53.3$ & $80.3 / 7.9$ \\
\hline & & 84-113 & 30.9 & $26.7-42.4$ & (79.04-81.38) \\
\hline \multirow[t]{2}{*}{ Sex } & 165 & Female & 66.7 & $59.4-73.9$ & \\
\hline & & Male & 33.3 & $26.1-40.6$ & \\
\hline \multirow[t]{5}{*}{ Marital status } & 164 & Single & 2.4 & $0-6.0$ & \\
\hline & & Married/ Living with a & 48.8 & $38.1-59.5$ & \\
\hline & & partner & 1.2 & 0.3 .6 & \\
\hline & & Separate/Divorced & 47.6 & $36.9-57.1$ & \\
\hline & & Widow & & & \\
\hline \multirow[t]{3}{*}{ Cognitive Impairment } & 141 & Severe & 18.9 & $12.4-25.4$ & $14.9 / 8.04$ \\
\hline & & Moderate & 55.9 & $47.7-64.1$ & $(13.57-16.22)$ \\
\hline & & Mild & 25.2 & $18.0-32.4$ & \\
\hline \multirow[t]{3}{*}{ BPSD prevalent symptoms } & 164 & Depression/dysphoria & 79.9 & $73.8-86.0$ & $6.6 / 2.62$ \\
\hline & & Anxiety & 72.6 & $65.9-79.3$ & $(6.16-6.95)$ \\
\hline & & Apathy & 69.5 & $62.2-76.2$ & \\
\hline \multirow[t]{5}{*}{ Functional Status } & 163 & Total dependence & 18.4 & $12.4-24.3$ & \\
\hline & & Severe & 14.7 & $9.2-20.1$ & \\
\hline & & Moderate & 12.9 & $7.7-18.0$ & $57.4 / 33.01$ \\
\hline & & Mild & 44.7 & $37.1-52.3$ & (52.33-62.46) \\
\hline & & Autonomous & 9.2 & $4.8-13.6$ & \\
\hline
\end{tabular}

Table 2 Demographic Characteristic of Caregivers

\begin{tabular}{|c|c|c|c|c|c|}
\hline Characteristic & $\mathrm{N}$ & & $\%$ & $95 \%$ IC & $\begin{array}{l}\text { Mean/sd } \\
95 \% \text { IC }\end{array}$ \\
\hline \multirow[t]{4}{*}{ Age } & 165 & $21-40$ & 13.9 & $9.1-19.4$ & \\
\hline & & $41-60$ & 46.6 & $38.8-53.9$ & $57.58 / 14.52$ \\
\hline & & $61-80$ & 36.4 & $29.1-43.6$ & $(55.33-59.97)$ \\
\hline & & $81-100$ & 3 & $0.6-6.1$ & \\
\hline \multirow[t]{2}{*}{ Sex } & 166 & Female & 81.9 & $76.4-88.5$ & \\
\hline & & Male & 18.1 & $11.5-23.6$ & \\
\hline \multirow[t]{4}{*}{ Marital status } & 166 & Single & 18.7 & $12.7-24.7$ & \\
\hline & & Married/ Living with a partner & 66.9 & $59.6-74.1$ & \\
\hline & & Separate/Divorced & 11.4 & $6.6-16.9$ & \\
\hline & & Widow & 3 & $0.6-6.0$ & \\
\hline \multirow[t]{4}{*}{ Relationship with PWD } & 165 & Spouse & 28.3 & $21.8-35.8$ & \\
\hline & & Daughter/son & 54.8 & $47.3-62.4$ & \\
\hline & & Other relative & 15 & $9.1-20.6$ & \\
\hline & & Friend & 1.8 & $0-4.2$ & \\
\hline
\end{tabular}


Table 3 Frequency (\%) of met and unmet needs of PWD (reported by caregivers)

\begin{tabular}{|c|c|c|c|c|}
\hline Needs of PWD & $\mathrm{N}$ & Met (\%) & Unmet (\%) & Total (\%) \\
\hline Accommodation & 163 & 28.9 & 8.44 & 37.3 \\
\hline Looking after home & 163 & 81.3 & 2.4 & 83.7 \\
\hline Food & 163 & 78.9 & 0,6 & 79.5 \\
\hline Self-Care & 162 & 75.3, & 3.0 & 78.3 \\
\hline Caring for another & 161 & 9.6 & 2.4 & 12.0 \\
\hline Daytime Activities & 163 & 39.8 & 39.2 & 79 \\
\hline Memory & 161 & 51.8 & 34.9 & 86.7 \\
\hline Eyesight/Hearing & 158 & 42.8 & 15.7 & 58.5 \\
\hline Mobility & 161 & 51.8 & 12.7 & 64.5 \\
\hline Continence & 163 & 53.6 & 7.2 & 60.8 \\
\hline Physical Health & 163 & 57.2 & 3.64 & 60.8 \\
\hline Drugs & 162 & 30.1 & 2.4 & 32.5 \\
\hline Psychotic Symptoms & 162 & 31.9 & 16.9 & 48.8 \\
\hline Psychological Distress & 162 & 39.2 & 21.1 & 60.3 \\
\hline Information & 162 & 22.3 & 27.1 & 49.4 \\
\hline Deliberate Self-harm & 163 & 9.6 & 1.8 & 11.9 \\
\hline Accidental Self-Harm & 163 & 43.4 & 4.2 & 47.6 \\
\hline Abuse/Neglect & 163 & 6.6 & 0.6 & 7,2 \\
\hline Behavior & 163 & 13.9 & 3.6 & 17.5 \\
\hline Alcohol & 163 & 43.6 & 1.2 & 4.8 \\
\hline Company & 163 & 24.1 & 36.1 & 60.2 \\
\hline Intimate Relationships & 163 & 21.1 & 3.6 & 24.7 \\
\hline Money & 163 & 82.5 & 2.4 & 84.9 \\
\hline Benefits & 162 & 36.7 & 13.9 & 50.6 \\
\hline Mean (s.d.) & & $10(3.8)$ & $3.3(2.8)$ & $13.3(4.5)$ \\
\hline
\end{tabular}

Table 4 Caregivers' factors related with unmet needs of People with Dementia

\begin{tabular}{lll}
\hline & Correlation & p-value \\
\hline PWD factors & & \\
$\quad$ Functional status (Barthel) & $\mathrm{Rs}=-.177$ & $.024^{*}$ \\
Caregiver factors & $\mathrm{Rs}=-.216$ & $.005^{* *}$ \\
Age & $\mathrm{K}-\mathrm{W}=7.307$ & $.026^{*}$ \\
Relationship with PWD & $\mathrm{Rs}=-.383$ & $.001^{* *}$ \\
Social Support (SS) & $\mathrm{Rs}=.372$ & $.001^{* *}$ \\
Burden (Zarit) & $\mathrm{Rs}=.260$ & $.001^{* *}$ \\
Anxiety Symptoms (HADS-A) & $\mathrm{Rs}=.354$ & $.001^{* *}$ \\
Depressive Symptoms (HADS-D) &
\end{tabular}

$\mathrm{Rs}=$ Rho de Spearman. $\mathrm{K}-\mathrm{W}=$ Kruskal Wallis test. Significant relations ${ }^{*} p<.05{ }^{* *} p<0.01$
0.01) were related with higher number of unmet needs in the person with dementia. The only factor of the PWD related with unmet needs was functional status. Higher dependence in the PWD was associated with higher number of unmet needs $\left(\mathrm{r}_{\mathrm{s}}=.177 ; p<0.05\right)$.

\section{Predictors of unmet needs}

A stepwise multiple linear regression analysis was carried on to determinate which of the factors were the best predictors to unmet needs (Table 5). The dependent variable was the number of unmet needs of PWD (reported by their caregivers). The independent variables were PWD's functional status, caregivers' age, social support, burden, anxiety and depressive symptoms and their relationship with PWD. Low social support $(p<0.01)$, high levels of burden $(p<0.05)$, younger caregivers $(p<0.05)$ and caregivers' anxiety symptoms $(p<0.05)$ were predictors of higher unmet needs of PWD $\left(\mathrm{F}=11.629 ; P<0.01 ; R^{2}=23 \%\right)$.

Social support and anxiety symptoms were the independent variables with the highest explanation power $(\beta=-0.163 ; \beta=0.122$, respectively). Multicollinearity was no present within the model.

\section{Discussion}

To our knowledge, the present study was the first in Latin America to assess the needs of people with dementia. Met and unmet needs of PWD were identified as well as factors associated with unmet needs.

Regarding the characteristics of PWD, it should be noted that, in our sample, the prevalence of BPSD was higher compared to the one found in community samples from developed countries, however, it is similar to other Chilean study [6]. The high frequency of BPSD could be explained because of the limited services available for people with dementia. In Chile, there is no provision of adequate pharmacological and non-pharmacological

Table 5 Predictors of unmet needs (Multiple Linear Regression Model). Dependent Variable: Unmet Needs of people with dementia

\begin{tabular}{lll}
\hline Variable & Beta & $(\mathrm{p})$ \\
\hline Social Support (SS) & -.163 & .001 \\
Burden (Zarit) & .031 & .030 \\
Caregiver's age & -.034 & .016 \\
Anxiety Symptoms (HADS-A) & .122 & .029 \\
Variance explained by model R2\% & $23 \%$ \\
Adjusted R2\% & $21 \%$ \\
$\mathrm{~F}=$ & 11.538 \\
Significant ( $\mathrm{p}$ ) & $<0.01$ \\
Variables Excluded of the model & Functional status (Barthel) \\
& Relationship with PWD \\
& Depressive Symptoms (HADS-D)
\end{tabular}


interventions aimed at managing BPSD. Since a strong association between BPSD and burden has been found in Chilean caregivers [6], it is important to address this issue through the implementation of the National Dementia Plan.

\section{Unmet needs of people with dementia in Chile}

In line with European samples where caregiver reports on the CANE were used, in our study, the most common PWD's unmet needs, reported by caregivers, were found in the areas of daytime activities, company, psychological distress and memory [10,33-36]. This result is consistent with a recent review about PWD's needs which pointed out that the most frequent unmet needs in this group are the same across countries irrespective of different supply and functioning of services [37]. In addition, in our sample, the mean number of unmet needs was higher than the average shown in most of European studies $[10,35,36]$. This could be reflecting both, a lower provision of services and the fact that most of caregiving assistance relies on family caregivers, consequently resulting in a higher number of unmet needs. Regarding this, it is important to mention that, in order to meet PWD's and caregiver's needs, Chilean public policies about dementia should try to address issues that currently are challenges for services in developed countries such as, adequate availability and timing, personalized and flexible offer, appropriate information and coordination, etc. [37].

\section{Factors associated with unmet needs}

The study showed that the most relevant met needs of PWD were related to the environmental and physical areas of dementia. These results are consistent with previous studies in high income countries, which revealed that basic needs of PWD are usually covered (food, home, personal care and physical health) $[10,35,36]$. A possible explanation is that those types of needs are easily identifiable and in most cases can be met by family caregivers without any additional support. In contrast, higher numbers of unmet needs were found in social and psychological areas. Considering caregivers' own burden and their mental health deterioration, providing PWD with daily activities to perform, information about their condition, help with memory loss and also company and support to psychological distress, could be aspects difficult to address. Usually, approaches to address dementia in Public Healthcare System are focused on older people's physical health, however, several studies have pointed out the relevance of psychosocial aspects in PWD $[8,38]$. The implementation of day-care centres for older adults with dementia is a relevant initiative to acknowledge the lack of activities and social isolation in this group. These centres not only improve the quality of life of PWD, through the development of social and physical activities in a safe environment, but also have a positive impact on caregivers by giving them respite time and consequently decreasing psychological distress [39, 40]. In Chile, this type of centres is recently being piloted in few cities of the country, and its number is expected to grow as long as they are included in the future National Care System.

\section{Predictors of unmet needs}

According to the results of this study, unmet needs of PWD were predicted only by caregivers' factors. Our two hypotheses were confirmed. Thus, caregivers' higher level of anxiety symptoms and burden, low perceived social support and younger age were related to a higher number of unmet needs in people with dementia. Different studies of Chilean caregivers of PWD have shown they have intense burden and high levels of depressive and anxiety symptoms $[6,41]$. It is not surprising that caregivers with these mental health characteristics were not in good condition for both, performing caregiving tasks and addressing unmet needs of those who they look after to, particularly in the psychosocial area. In Chile, most older people expect being cared for by their families [42]. In addition, worldwide, it has been encouraged that, in order to have better health outcomes, older adults should stay at home for as long as possible [35]. However, this can be achieved only under the presence of a health and social care system which provides strong support for PWD and their caregivers. In Chile, a relevant initiative targeting this matter is being piloted, a new public programme called "Chile Cuida" ("Chile Provides Care"). This programme intends to give some relief to informal caregivers, to create new jobs and to promote better conditions for older people to stay in their own households. People who live within the family caregiver's neighborhood or community are trained to become a formal caregiver, making them capable and formally prepared to provide assistance to PWD in their households twice per week for 3 or $4 \mathrm{~h}$ a day. This visit gives respite to family caregivers who also have the opportunity to participate in workshops with health professionals, training sessions or recreational activities [34]. In addition, the National Dementia Plan has been recently launched by the Minister of Health and is starting to be piloted in few cities of the country. This policy aims to address psychosocial aspects of dementia, for example, through the implementation of day-care centres across the country, improving the coordination between primary and secondary health and giving treatment to the PWD-caregiver dyad. [9].

Caregiver's age was also found to be a predictor of PWD's unmet needs. Younger caregivers are usually daughters of PWD who already have multiple 
responsibilities. It has been found that younger caregivers usually have to take care of their own children, comply with professional duties and social life events. Additionally, they tend to experience less feelings of reward from being a caregiver and show higher levels of burden compared to older caregivers [43]. These issues add difficulties to meet PWD's unmet needs.

\section{Limitations and strengths}

To our knowledge, the present study is the first to assess the needs of older PWD in a Latin American country (Chile). It was carried out with a relevant sample size and included measures for community-dwelling PWD and caregivers. Nevertheless, there are some limitations and suggestions to consider for further research. Even though all the participants had a degree of cognitive impairment, dementia diagnosis was not always given by a specialist physician (geriatrician, neurologist, etc) which might have biased the selection of participants [44]. Despite this, the sample is representative of Chilean reality where most PWD get their first approach to a diagnosis by a general practitioner, not by a specialist. In addition, this research considered older people with any kind of dementia. It is suggested that future research focuses on persons with specific types of dementia whose needs could differ according to particular diagnoses [45, 46]. We should be cautious to extrapolate our results to all dementia patients since our sample comprises subjects who do have a diagnosis. Other studies show that roughly one half of those, who would meet the diagnostic criteria for dementias, have been diagnosed $[47,48]$. According to current evidence, patients with a diagnosis of dementia are more severely impaired therefore could present more needs compared to under-diagnosed subjects [49]. Also, the sample of our study was a convenience sample, known to services and from urban areas, consequently, the results cannot be generalized to Chilean PWD not known to services and/or living at rural areas. In order to reflect the prevalence of needs, future research could consider an epidemiological population-based sample therefore making the results more generalizable.

Finally, in this study, PWD's needs where rated by caregivers and thus, their views on the needs of their relative could have been influenced by their own physical and mental health. However, literature has shown that, even though PWD rate less unmet needs than their caregivers, they agree on most frequent areas where they are not receiving the right help [10,35]. Future research could include a description of needs according to the point of view of older persons with dementia. In addition, it is important to mention that caregiver's factors and caregiver's perspective on PWD's unmet needs could be mutually affected. For example, a high level of caregiver's burden could lead to a higher number of PWD's unmet needs or viceversa. Previous studies using the CANE have considered, indistinctly, the concept of "unmet needs" either, as a result or as a predictor of caregiver's state [10,33, 36, 50]. Longitudinal research is needed in order to determine causality.

\section{Conclusion}

The results of this research revealed the urgent need to address the psychological and social aspects of dementia, because most frequent PWD's unmet needs and their predictors pointed out to deficiencies in those areas. The fact that only caregivers' factors were predictors of PWD's unmet needs confirms the relevance of treating both, the PWD and their caregivers, as a dyad who influences each other. Caregiver's lack of social support, high levels of burden, presence of anxiety symptoms and lower age were predictors of unmet needs in people with dementia. Considering these results, it is expected that, in the years coming, recently implemented national policies and care initiatives, could meet most common PWD's unmet needs both, directly and through addressing caregivers' issues. In order to achieve this, it is very important, first, to expand and evaluate the implementation of those policies, and second, carrying out future research on needs to find out whether they are being addressed or not.

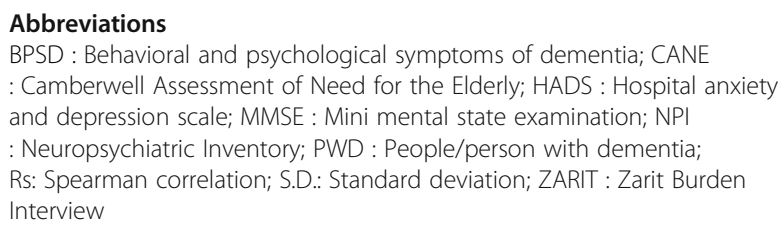

\section{Acknowledgements}

We would like to thank all of the persons with dementia and their caregivers who gave their time to participate in this study.

\section{Funding}

This research was supported by the National Fund for Scientific and Technological Development (FONDECYT) Projects N¹141279 and 11100457 , by the Fund for Innovation and Competitiveness (FIC) of the Chilean Ministry of Economy, Development and Tourism, through the Millennium Science Initiative, Grant N ${ }^{\circ}$ IS130005 (awarded to CMC) and the FONDAP Program Grant 15150012 (awarded to AS).

None of the funding bodies played any role in the design of the study; collection, analysis and interpretation of data; and in writing the manuscript.

\section{Availability of data and materials}

The datasets used and/or analysed during the current study are available from the corresponding author on reasonable request.

\section{Authors' contributions}

All author participated in the article preparation. TTM, ASC, MLC and CMC read and approved the final manuscript. Study concept and design: ASC, MMO, ACU and GR. Analysis and interpretation of data: TTM, MLC and CMC. Drafting of the manuscript: TTM, MLC and CMC. Revision of the manuscript: TTM, ASC, MLC and CMC. All authors approved the final manuscript. 


\section{Ethics approval and consent to participate}

This research was approved by the Bioethical Committee of the Faculty of Medicine, Universidad de Valparaíso, reference number 17/2013. Written informed consent was obtained from caregivers and people with dementia. Assent was obtained from people with dementia who was not able to provide written informed consent.

\section{Consent for publication}

Not applicable.

\section{Competing interests}

The authors declare that they have no competing interests.

\section{Publisher's Note}

Springer Nature remains neutral with regard to jurisdictional claims in published maps and institutional affiliations.

\begin{abstract}
Author details
${ }^{1}$ Mailman School of Public Health, Columbia University, New York, USA. ${ }^{2}$ Gerosciences Center for Brain Health and Metabolism (GERO), Santiago, Chile. ${ }^{3}$ Neuropsychology and Clinical Neuroscience Laboratory (LANNEC), Physiopathology Department, Faculty of Medicine, Universidad de Chile, Santiago, Chile. ${ }^{4}$ Physiopathology Department, ICBM, Neurosciences Department, East Neuroscience Department, Faculty of Medicine, Universidad de Chile, Santiago, Chile. ${ }^{5}$ Memory and Neuropsychiatric Clinic (CMYN) Neurology Department, Hospital del Salvador \& University of Chile, Santiago, Chile. 'Servicio de Neurología, Departamento de Medicina, Clínica Alemana-Universidad del Desarrollo, Santiago, Chile. ${ }^{7}$ Universidad Andres Bello, Faculty of Nursing, Sazié 2212, Santiago, Chile. ${ }^{8}$ Millennium Institute for Research in Depression and Personality (MIDAP), Santiago, Chile.

${ }^{9}$ Departamento de Filosofía y Psicología, Universidad de Tarapacá, Arica, Chile. ${ }^{10}$ Facultad de Medicina, Universidad de Valparaíso, Valparaíso, Chile.
\end{abstract}

\section{Received: 4 December 2017 Accepted: 5 April 2019}

\section{Published online: 15 April 2019}

\section{References}

1. Alzheimer's-Report, 2016. Alzheimer's disease facts and figures. Alzheimers Demen. 2016;12(4):459-509.

2. World Health Organization. Fact Sheet Dementia. 2016.

3. World Health Organization. In: World Health Organization, 2012, editor Dementia: a public health priority. Geneva; 2015. ISBN 978-92-4-156445-8.

4. Gajardo J, Monsalves MJ. Demencia, un tema urgente para Chile. Revista Chilena de Salud Pública. 2013;17(1):22-5.

5. Rizzi L, Rosset I, Roriz-Cruz M. Global epidemiology of dementia: Alzheimer's and vascular types. Biomed Res Int. 2014;2014:908915.

6. Slachevsky A, et al. The CUIDEME study: determinants of burden in chilean primary caregivers of patients with dementia. J Alzheimers Dis. 2013;35(2): 297-306.

7. Fuentes P, Albala C. An update on aging and dementia in Chile. Dementia Neuropsychol. 2014;8(4):317-22.

8. Gajardo J, Abusleme MT. Plan Nacional de Demencias: Antecedentes Globales y Síntesis de la Estrategia Chilena. Revista Médica Clínica Las Condes. 2016;27(3):286-96.

9. Ministerio de Salud. Documento Preliminar para la elaboración del Plan Nacional para las demencias. G.d. Chile, Editor 2015.

10. Miranda-Castillo C, Woods B, Orrell M. The needs of people with dementia living at home from user, caregiver and professional perspectives: a crosssectional survey. BMC Health Serv Res. 2013;13(1):43.

11. Willemse BM, et al. Staff-resident interactions in long-term care for people with dementia: the role of meeting psychological needs in achieving residents' well-being. Aging Ment Health. 2015;19(5):444-52.

12. Zwaanswijk M, et al. Informal caregivers of people with dementia: problems, needs and support in the initial stage and in subsequent stages of dementia: a questionnaire survey. Open Nurs J. 2013;7:1.

13. Tretteteig S, Vatne $\mathrm{S}$, Rokstad AMM. The influence of day care centres for people with dementia on family caregivers: an integrative review of the literature. Aging Ment Health. 2016;20(5):450-62.

14. Black BS, et al. Unmet needs of community-residing persons with dementia and their informal caregivers: findings from the maximizing Independence at home study. J Am Geriatr Soc. 2013;61(12):2087-95.
15. Cohen-Mansfield J, et al. Which unmet needs contribute to behavior problems in persons with advanced dementia? Psychiatry Res. 2015;228(1):59-64.

16. Feast $A$, et al. A systematic review of the relationship between behavioral and psychological symptoms (BPSD) and caregiver well-being. Int Psychogeriatr. 2016:1-14.

17. Thrush A, Hyder A. The neglected burden of caregiving in low-and middleincome countries. Disabil Health J. 2014;7(3):262-72.

18. Hojman DA, et al. The cost of dementia in an unequal country: the case of Chile. PLoS One. 2017;12(3):e0172204.

19. Custodio $\mathrm{N}$, et al. Dementia in latin america: epidemiological evidence and implications for public policy. Front Aging Neurosci. 2017;9:221.

20. Quiroga P, Albala Brevis C, Klaasen G. Validation of a screening test for age associated cognitive impairment, in Chile; 2004.

21. Orrell M, Hancock G. CANE: Camberwell assessment of need for the elderly: Gaskell London; 2004.

22. Ybarzábal Mesa, M., et al., Validación de la versión española del CANE. Escala de evaluación de necesidades para ancianos de Camberwell. 2002.

23. Cid-Ruzafa J, Damián-Moreno J. Valoración de la discapacidad física: el índice de Barthel. Revista española de salud pública. 1997;71(2):127-37.

24. Cummings $\mathrm{J} L$, et al. The neuropsychiatric inventory comprehensive assessment of psychopathology in dementia. Neurology. 1994;44(12):2308.

25. Musa G, et al. Utility of the neuropsychiatric inventory questionnaire (NPI-Q) in the assessment of a sample of patients with Alzheimer's disease in Chile. Demen Neuropsychol. 2017;11(2):129-36.

26. Boada M, et al. Neuropsychiatric inventory questionnaire (NPI-Q): Spanish validation of an abridged form of the neuropsychiatric inventory (NPI). Neurologia (Barcelona, Spain). 2001;17(6):317-23.

27. Breinbauer $\mathrm{H}$. Validación en Chile de la escala de sobrecarga del cuidador de Zarit en sus versiones original y abreviada: Réplica a corrección. Rev Med Chil. 2013;141(8):1084.

28. Quintana J, et al. Evaluation of the psychometric characteristics of the Spanish version of the hospital anxiety and depression scale. Acta Psychiatr Scand. 2003;107(3):216-21.

29. Zimet GD, et al. Psychometric characteristics of the multidimensional scale of perceived social support. J Pers Assess. 1990;55(3-4):610-7.

30. Arechabala M, Miranda C. Validation of a scale of perceived social support in a group of elders under control in a hypertension program in the metropolitan region. Ciencia y Enfermería. 2002;8(1):49-55.

31. Arbuckle JL. IBM SPSS Amos 19 user's guide, vol. 635. Crawfordville: Amos Development Corporation; 2010.

32. SPSS I. IBM SPSS statistics base 20. Chicago: SPSS Inc; 2011.

33. Bakker $C$, et al. Unmet needs and health-related quality of life in youngonset dementia. Am J Geriatr Psychiatry. 2014;22(11):1121-30.

34. Freyne A, Dolan M, Cooney C. Carer-rated needs assessment of a cohort of people with dementia. Ir J Psychol Med. 2010;27(2):72-6.

35. Mazurek J, et al. Met and unmet care needs of the elderly with dementia living at home: personal and informal carers' perspectives. Dementia (London). 2017:1471301217733233.

36. van der Roest $\mathrm{HG}$, et al. What do community-dwelling people with dementia need? A survey of those who are known to care and welfare services. Int Psychogeriatr. 2009;21(5):949-65.

37. Morrisby C, Joosten A, Ciccarelli M. Do services meet the needs of people with dementia and carers living in the community? A scoping review of the international literature. Int Psychogeriatr. 2018;30(1):5-14.

38. Cadieux M-A, Garcia LJ, Patrick J. Needs of people with dementia in longterm care a systematic review. Am J Alzheimers Dis Other Dement. 2013;28:723-33.

39. Servicio Nacional del Adulto Mayor. Política Integral de Envejecimiento Positivo para Chile 2012-2025, M.D. Social, Editor 2012.

40. Servicio Nacional del Adulto Mayor. Guía de Operaciones Centros Diurnos. 2015.

41. González S, Rossel J, Campos T. Sobrecarga en cuidadores informales de personas aquejadas de demencia en la región Metropolitana de Chile. In: Personas Mayores y Demencia: Realidad y Desafíos. Pontificia Universidad Católica: Centro UC Estudios de vejez y envejecimiento; 2015. p. 65-84.

42. Programa Adulto Mayor UC and Centro UC Estudios de Vejez y Envejecimiento, CHILE Y SUS MAYORES. Resultados IV Encuesta Calidad de Vida en la Vejez: Pontificia Universidad Católica de Chile; 2016.

43. Espín Andrade AM. Factores de riesgo de carga en cuidadores informales de adultos mayores con demencia. Revista Cubana de Salud Pública. 2012; 38(3):493-02. 
44. Olavarría L, et al. Percepción de conocimiento sobre las Demencias en Profesionales de la Salud de Chile. Rev Med Chil. 2016;144(10):1365-8.

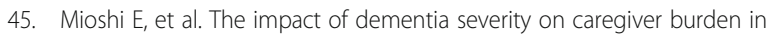
frontotemporal dementia and Alzheimer disease. Alzheimer Dis Assoc Disord. 2013;27(1):68-73.

46. Uflacker A, et al. Caregiver burden in atypical dementias: comparing frontotemporal dementia, Creutzfeldt-Jakob disease, and Alzheimer's disease. Int Psychogeriatr. 2016;28(02):269-73.

47. Kotagal V, et al. Factors associated with cognitive evaluations in the United States. Neurology. 2015;84(1):64-71.

48. Nakamura $A E$, et al. Dementia underdiagnosis in Brazil. Lancet (London, England). 2015;385(9966):418.

49. Hurd MD, et al. Monetary costs of dementia in the United States. N Engl J Med. 2013;368(14):1326-34.

50. Park $\mathrm{M}$, et al. The roles of unmet needs and formal support in the caregiving satisfaction and caregiving burden of family caregivers for persons with dementia. Int Psychogeriatr. 2018;30(4):557-67.

Ready to submit your research? Choose BMC and benefit from:

- fast, convenient online submission

- thorough peer review by experienced researchers in your field

- rapid publication on acceptance

- support for research data, including large and complex data types

- gold Open Access which fosters wider collaboration and increased citations

- maximum visibility for your research: over $100 \mathrm{M}$ website views per year

At $\mathrm{BMC}$, research is always in progress.

Learn more biomedcentral.com/submissions 